\title{
A case of ST-segment elevation myocardial infarction due to intra-articular lidocaine instillation
}

\section{Bojana Gardijan*, Matija Marković, Darko Počanić, Tomislav Letilović}

University Hospital Merkur, Zagreb, Croatia
RECEIVED:

February 9, 2016

ACCEPTED:

February 20, 2016
KEYWORDS: ST-segment elevation myocardial infarction, lidocaine, vasospasm. CITATION: Cardiol Croat. 2016;11(3-4):97-98. | DoI: http://dx.doi.org/10.15836/ccar2016.97 *ADDRESS FOR CORRESPONDENCE: Bojana Gardijan, Klinička bolnica Merkur, Zajčeva 19, HR-10000 Zagreb, Croatia. / Phone: +385-98-1650-393 / E-mail: bojana.gardijan@gmail.com

ORCID: Bojana Gardijan, http://orcid.org/0000-0002-1768-2277 • Matija Marković, http://orcid.org/0000-0002-2852-3730 Darko Počanić, http://orcid.org/0000-0003-3257-110X • Tomislav Letilović, http://orcid.org/0000-0003-1229-7983

|IIIIIIIIIIIIIIIIIIIIIIIIIIIIIIIIIIIIIIIIIIIIIIIIIIIIIIIIIIIIIIIIIIIIIIIIIIIIIIIIIIIIIIIIIIIIIIIIIIIIIIIIIIIIIIIIIIIIIIII

Introduction: Lidocaine is an essential drug used as a local anesthetic and as antiarrhythmic medication of the class Ib type. There are multiple reports in literature that lidocaine can cause coronary artery spasm both in vitro and in vivo ${ }^{1,2}$. Elevation of the ST-segment is described during dental or neurosurgical procedures using locoregional lidocaine anesthesia ${ }^{2,3}$. We present a case in which intra-articular lidocaine instillation caused a vasospastic ST-segment elevation myocardial infarction (STEMI).

Case: A 49-year-old male patient presented to the emergency clinic with chest pain that had begun an hour ago. The pain occurred at rest, was independent of exertion and radiated to the left arm. Previously that morning, he was at the surgical outpatient clinic due to a chronic knee condition where he underwent punction and intra-articular instillation of $100 \mathrm{mg}$ lidocaine. The chest pain started 30 minutes after the procedure. The patient had never experienced chest pain or intolerance of exertion before. Previous medical history was notable for well-controlled arterial hypertension, without any family history of coronary artery disease. He previously received lidocaine anesthesia without complications and had no known allergies. There was $1 \mathrm{~mm}$ elevation in leads II, III, aVF and inferior STEMI was diagnosed (Figure 1). The patient was transferred to the catheterization laboratory for primary percutaneous coronary intervention. The coronary arteriography was without any evidence of

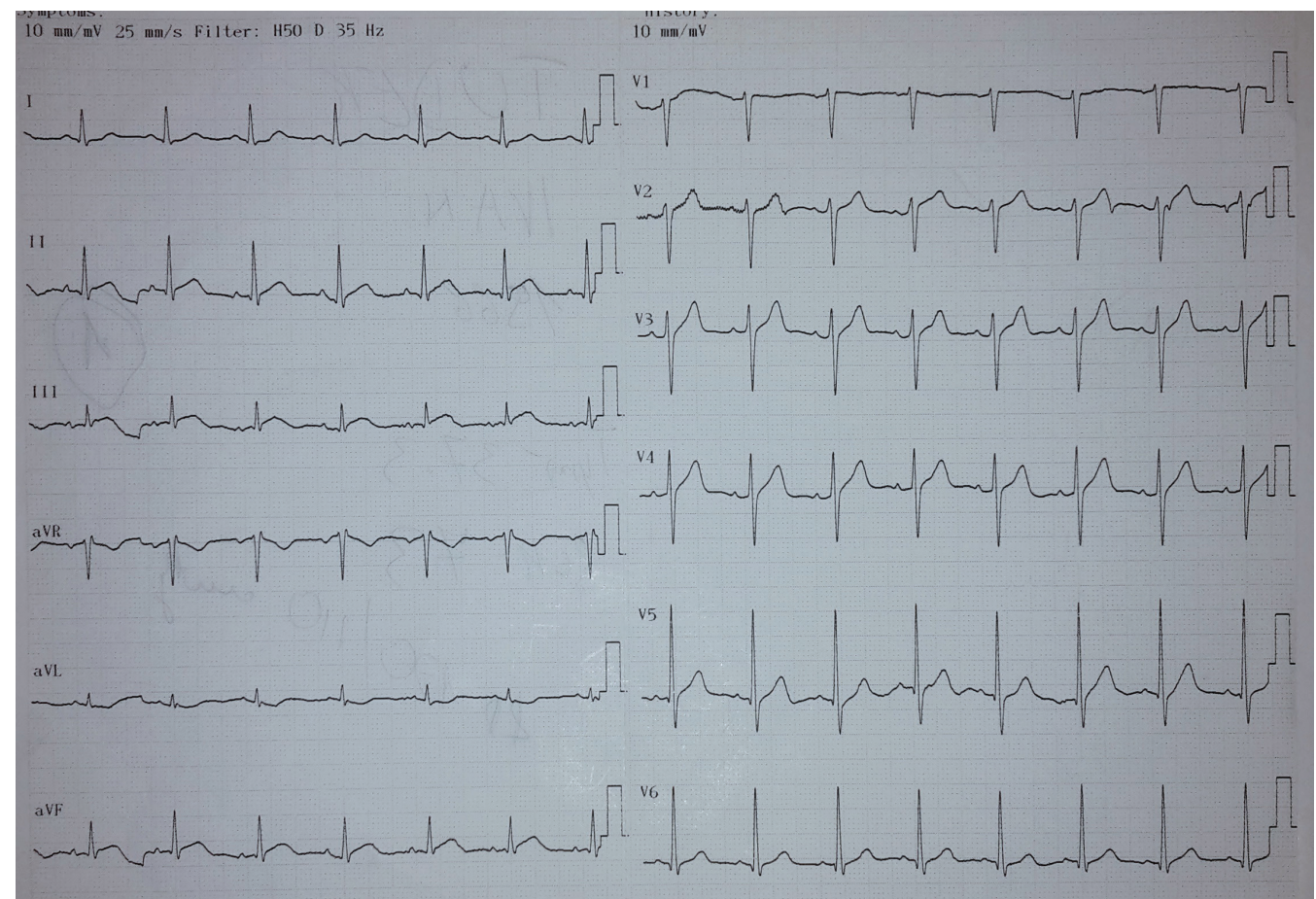

FIGURE 1. The 12-lead electrocardiogram recording on admission showing discrete ST-segment elevation in inferior leads. 
stenosis (Figure 2). The patient received protocol STEMI care. Echocardiography showed no abnormalities or regional wall motion abnormalities. The initial high-sensitivity cardiac-specific troponin I was beneath the value of detection, with the peak value on the second day of stay, $4678.3 \mathrm{ng} / \mathrm{L}$ (reference value $<34.2 \mathrm{ng} / \mathrm{l}$ ). He also developed negative $\mathrm{T}$ waves in the inferior leads, as well as Q wave in the inferior leads (Figure 3). Throughout the hospital stay he was hemodynamically stable and reported no pain or chest-discomfort. The follow-up echocardiography showed no regional wall motion abnormalities.

We concluded that the intraarticularly instilled lidocaine was absorbed into the blood stream and caused the vasospasm that lead to the STEMI. Although similar events have been described during other procedures, to our knowledge this is a first report of such an association during intra-articular lidocaine instillation.
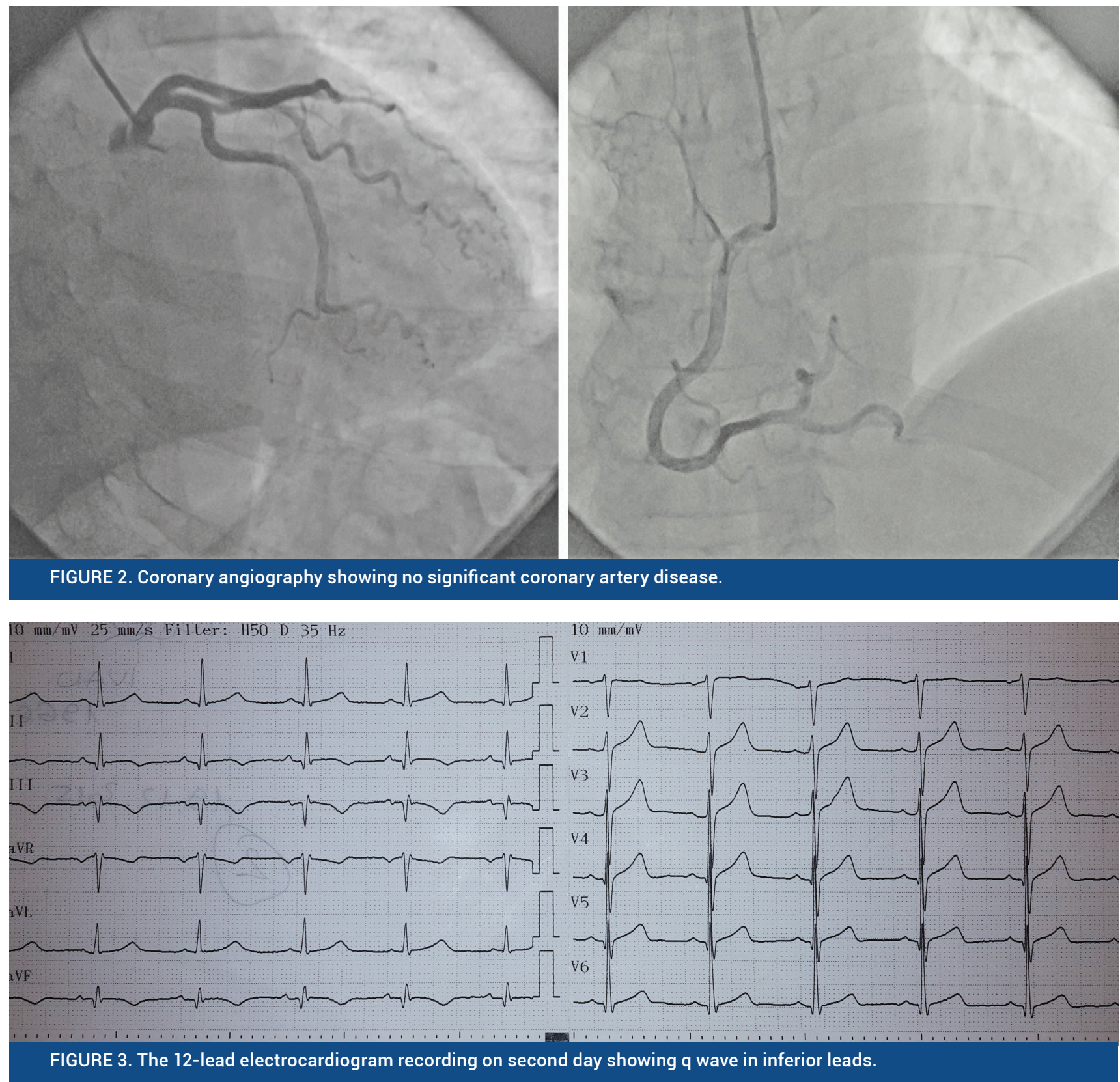

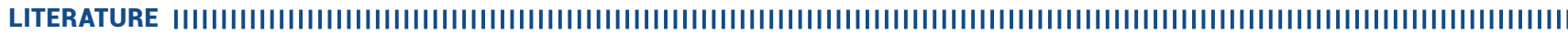

1. Gur 0, Ege T, Gurkan S, Ozkaramanli Gur D, Karadag H, Cakir H, et al. In vitro effects of lidocaine hydrochloride on coronary artery bypass grafts. J Cardiovasc Surg (Torino). 2012;53(5):665-9. PubMed: http://www.ncbi.nlm.nih.gov/pubmed/22669098

2. Kawanishi S, Mizobuchi S, Matsumi M. [Case of coronary vasospasm during lumbar discectomy in prone position]. Masui. 2011 Jun;60(6):718-20. PubMed: http://www.ncbi.nlm.nih.gov/pubmed/2171077

3. González Enríquez S, de la Torre Hernández JM, Sainz Laso F. [Clinical episode of suggestive left main coronary artery spasm after gingival anaesthetic infiltration]. Rev Esp Cardiol. 2003:56(10):1033-4. DOI: http://dx.doi.org/10.1157/13052397 